\title{
Research on Interpreters' Professional Development under the Background of "The Belt and Road" Construction
}

\author{
Juan Lu \\ School of Foreign Studies, Shaanxi Sci-Tech University, HanZhong 723000, Shaanxi, China
}

672241343@qq.com

\begin{abstract}
Keywords: Interpretation; Professional development; "The Belt and Road" construction; Interdisciplinary approach
\end{abstract}

\begin{abstract}
On November 8, 2014, the General Secretary Xi announced that China would invest \$ 40 billion to set up the "Silk Road Fund", aiming to provide financial support for the infrastructure construction, resource development, industrial cooperation, and other relevant projects of "The Belt and Road" Construction. Language barrier and road blocking is the most outstanding difficulty in the process of "The Belt and Road" Construction, which has hindered its forward development. Qualified interpreters has been always in short supply because the available interpreters in current market can't meet the demand of "The Belt and Road" Construction. So, firstly, this paper will study what kind of interpreters are the most urgent-needed interpreters in "Silk and Road" Construction. Secondly, this paper will study how to transform the traditional interpreters to adapt to the new social need in order to promote the process of "The Belt and Road" Construction.
\end{abstract}

\section{Introduction}

Since China's "The Belt and Road" Construction policy was proposed by the central government, all the foreign language studies universities and institutions began to change their foreign language talents training models and reformed their syllabus for foreign language teaching. A lot of reform methods were rendered by lots of foreign experts, such as taking business English and trade English as the leading majors, increasing the kinds of minority language, combining the concrete technology with English. But little improving method was proposed for interpretation and interpreters, which is caused by the underdeveloped research of interpretation subject. China's "The Belt and Road" Construction will definitely create a new international and domestic environment while only when interpreters adapted themselves to the social demand, could they be qualified and competent for their work.

\section{Choosing a Practical Translation Field as the Main Interpretation Direction in The Future}

In China, interpretation study started comparatively late but is developing at a fast speed. The focus of the study has been shifted from accumulation of pure experience and listing the existed problems in early days to in-depth theoretical study; from a static one focusing on the principles and standards of interpretation to a dynamic one concentrating on the process of interpretation and the mental work of the interpreter; and from an isolated investigation of interpretation itself to an open interdisciplinary research associated with various relevant fields [1]. And this paper studies the interpretation with an interdisciplinary approach.

Current Situation and Problems of Interpretation. At present, our country's interpreters are translating for all kinds of conference and all subjects, from politics, business, and trade, tourism to academics, technology, information science and medical science, which caused lots of translation problems. Lots of translation mistakes occurred in their interpretation because the lack of the relevant professional knowledge and technology. The common interpreters may translate properly the political conference and commercial conference, but they will always do some improper translation or even make mistakes in science and engineering conference because most of the interpreters are English-based major, so they don't know the terminology and they cannot understand the complex scientific theory and the sophisticated principle of machinery. For example, 
a English-background interpreter could not translate a conference about medical summit because the complicated medical theory is difficult to understand for a non-medicine major interpreter, let along to translate. That is why the current interpretation quality in China is not unqualified and the qualified interpreters are urgent-needed.

English-based interpreters cannot translate the terminologies in other subject while non-English major interpreters perform very well in conference. In many conferences, it's not difficult for us to find interpreters whose major is information science, medicine, computer, engineering and so on. Their translation is better than English-background because the polytechnic interpreters have encyclopedic knowledge and divergent thinking whiles the linguistic interpreter's vision is relatively restricted and their scope of knowledge is narrow. So, in interpretation practice, although the non-English major interpreters have less linguistic skills, they can understand the source speech better because of their background knowledge and different thinking model. Although English-major interpreters have a solid language foundation, they just translate the literal meaning word for word while can't comprehend the profound connotation of the source speech. To some extent, to interpret is to interpret the speaker's thinking, the underlined culture of the source speech, the theory of the science, so for a qualified interpreter, he or she not only should be equipped with solid language foundation, but also should be equipped with the relevant background professional knowledge, information, theory and culture[2].

The Future Demand of the Interpretation Market under the Background of "The Belt and Road" Construction. "The Belt and Road" Construction will deepen the cooperation field between China and the other country in the word, so it requires interpreters to specify and refine their major. In the past, a interpreter, no matter with linguistic background or not, can translate all kinds of conference with law subject, science subject, philosophy Subject and so on. But with the deepening and broadening of the reform and opening up under the background of "The Belt and Road" Construction, interpreters cannot translate all kinds of conference with different subject. So "The Belt and Road" Construction requires interpreters to have their own concrete and specialized major, which means that except linguistic skills, interpreters should specialize the exclusive translation field. For example, medical conference needs medical interpreters; IT conference needs IT interpreters; and machinery conference needs machinery interpreters. Traditional interpreters only with linguistic skills will be out of date in future translation market, and to prepare for the "The Belt and Road" Construction, interpreters who just know language and translation should study another specialty as his or her second major according to personal interest and the practical cooperation field of "The Belt and Road" Construction. In future, translation will be divided into different branch because the demand of The Belt and Road" Construction, such as Communications, finance, trade, transportation, energy and resource, diplomatic relation and regional defense security, information science and so on. Professional interpreters should foresighted the developing trend of interpretation and choose one of them as his or her own major to fully prepare for "The Belt and Road" Construction. Language is just a tool, which just works as a carrier of knowledge and culture to communication with foreigners, so it's not the knowledge let alone the major. In translation, language is not the most important thing while the most important thing in interpretation is the content of the language. To make the audience understand the speaker, it's the prerequisite that the interpreter should understand the source speech firstly. To understand the speaker do not equals to understand his or her linguistic symbols, it means to understand the content, information, meaning and communication purpose of the source speech. An interpreter who just knows superficial language is not qualified in future translation market; he or she must be equipped with both language tool and the second major.

\section{Preparing Minority Language as the Interpretation Language}

Comparatively speaking, China's interpretation development lags far behind the developed countries. Currently, most of China's interpreters are English background and they just can do E-C or C-E interpretation. Little interpreters can do simultaneous interpretation from Chinese to Italy, Russian, Germany, Japanese, Korean, and Spanish and so on. Sometimes, they can do consecutive 
interpretation with minority language, but they can't do simultaneous interpretation with minority language ${ }^{[3] .}$

Reform and Opening up Construction Mainly Needs Interpreters with English as Their Working Language. Thirty years ago, China's reform and opening up policy aims to communicate and cooperate mainly with America and western countries in order to take advantage of the capital, advanced technology and management experience of the developed countries. Because the cooperation field with America and Western countries has been saturated, in order to create new market and expand domestic demand, China has proposed "The Belt and Road" Construction policy, which aims to communicate and cooperate with Asian countries, African countries, and central eastern European countries. The reform and opening up mainly concerned the English speaking countries, so English naturally become the leading working language in foreign cooperation while "The Belt and Road" Construction involves more than 65 countries, including the 10 countries in ASEAN, 18 countries in western Asia, 8 countries in South Asia, 5 countries in Central Asia, the 7 countries of CIS and 16 countries in central eastern Europe ${ }^{[4]}$. Obviously, interpreters with English as their working language are no longer the most urgent-needed talents in "The Belt and Road" Construction while interpreters with the minority language as their working language are urgently needed.

"The Belt and Road" Construction Needs Interpreters with Minority Language as Their Working Language. To serve for "The Belt and Road" Construction, interpreter trainees should study minority language as their working language, such as French, Russian, Germany, Spanish, Korean, Italy and so on. Nowadays, the lack of small language talents has already caused barrier to the process of "The Belt and Road" Construction. Some cooperative countries are not English-speaking country and their official language or second official language is not English while little interpreters can translate the minority language, which resulted in the Suspension of the cooperation. Recent years, Shanghai Foreign Language Studies University, Beijing Foreign Language Studies University and Guangdong Foreign Language Studies University all opened the small language interpretation major. Bilingual or multilingual foreign languages talents' competitiveness in the talent market is much higher than the monolingual foreign language talents. So interpretation students or trainees should choose the small language as their working language in order to improving their competitiveness in future society, and the English-background interpreters should strengthen their second language in case that their English language couldn't satisfy their translation demand in the future ${ }^{[5]}$.

Most of the universities in China focus on cultivating English interpreters and haven't offered simultaneous interpretation class for the students whose major is minority language, which is not reasonable. More seriously, in China's western region, most of the universities offer the second language for English major students even in their Bachelor degree study period, but many students never pay much attention to the second language study, they think the second language is insignificant and the English is their major with which they can make a living. In fact, the English talents have already been saturated and their second language may help them to find a job. So the whole society, including both the educators and students should attach importance to the study of the minority language rather than neglecting it.

\section{Improving Interpreters' Ability of Cross-Cultural Communication}

"The Belt and Road" Construction involves more than 65 countries and cross over many regions while every country has its' own culture and customs. Language is the barrier of culture and to comprehend language is to comprehend the culture of the nation. So in "The Belt and Road" Construction, culture translation will be the most difficult problem in interpretation. In order to resolve the cultural problem, interpreters should not only study the historical culture, the religious culture, the economical culture and the geographical culture of the relevant countries, but also their life customs, social etiquette, communication ways, euphemism, taboos and so on, because interpretation actually is a cross-cultural communication activity, if interpreters want to make the audience understand them better, they must know their audience's society, culture and ideology. As 
Wang Zuoliang says, in translation and interpretation, we should take the reader's or audience's care into consideration. Translators and interpreters must have a correct evaluation about the hearer's culture. Gile holds speakers always assume that the audience shares the knowledge and culture with them. But actually, the mutual cultural environments between the speaker and audience are different. The interpreter who works as the intermediary of communication should bridge the cultural gap between the speaker and audience. It's the interpreter's duty to make what the speaker says quickly understood by the hearer.

Interpretation Is Actually a Kind of Cross-Cultural Communication Action. According to Gile, interpretation is an intentional, interpersonal and intercultural communication, which involves two processes: decoding and encoding ${ }^{[6]}$. Decoding is the communication between the interpreter and the message originator while encoding is the communication between the interpreter and the message receiver. In these two processes, the interpreter, instead of being a passive mouthpiece which will one or two minutes later repeat the message in another language to the audience, is communicating with the two ends of the communication line actively all the time. In the decoding process, the interpreter who communicates with the speaker should be faithful to the message originator's culture while in the encoding process; the interpreter who communicates with the audience should be faithful to the message receiver's culture. Besides, the interpreter should also make the target speech faithful to the target language's culture and custom. Otherwise, any distortion of the source message will bring about disastrous outcome. Interpreters' misinterpretation may trigger war in the conference of United Nations; may result in the suspension of diplomatic relationship in the reception of foreign official; may lead to the break of cooperation in the business negotiation.

Interpreters Should Achieve the Cultural Identification with Both the Speaker and the Audience. A qualified interpreter must achieve cultural identification with both the speaker and the audience and must be faithful to both the speaker and the audience. However, being faithful to the speaker does not refer to being faithful to the lexicon, grammar, and syntax of source utterance. According to Gile, being faithful to the message originator means that interpreters should maximize the possibility of mirroring the speaker's mind and thinking, and dig out the cultural meaning of the speech. In cross-cultural communication, we always concerned with the cultural meaning of the speech because the cultural meaning may leads to difficulty and problem of international communication. To keep faithful to the message receiver, the interpreter needs to make extra effort for achieving the mutual identification of cultural cognition between himself or herself and the receiver. That is to say. Interpreters should analyze audience's cultural background, such as audience's education, profession, social status, religion, group attitude, common needs and so on [7]. According to Gile, if the interpreter wants to keep faithfulness to the message receiver, he or she must take the cultural factor into consideration.

The interaction in interpretation derives from the discrepancy between interlocutors in many different aspects. Cultural difference is the key aspect which causes interpreting interaction to occur. The different culture decides different thinking pattern, different expression method and different expression custom ${ }^{[8]}$. On many occasions, speakers of different languages do not understand one another. It is not because their languages cannot be mutually translated into one another. It is because they do not share the same way of viewing and understanding events and they do not agree on the meaning and the value of the concepts underlying the words. That is to say. They do not share the same cultural framework underlying the linguistic symbols. Culture and language are integrated. Culture is embedded in language and language expresses culture reality. Culture is one of the filters which restrict the way people perceive, comprehend, and communicate ${ }^{[9]}$. So the interpreter should aspire to be a cultural mediator rather than a mere "mouthpiece" for the actual speaker.

\section{Conclusions}

The Belt and Road construction policy has brought a new dawn for foreign language talents in China because the construction of the Silk Road stretches across three continents: Asia, Europe and 
Africa, which will provide huge employment market for foreign language talents. Under the background of "The Belt and Road" Construction, Interpreters will obtain lots of new opportunities. Meanwhile, they will definitely encounter some severe challenges because of the different cooperation countries and different cooperation field ${ }^{[10]}$. However, The Belt and Road construction no longer needs the traditional pure language interpreters while urgently needs Inter-disciplinary small language interpreters. Therefore, the traditional interpreters in China must transform themselves into "Inter-disciplinary research type, Inter-disciplinary major type, Inter-disciplinary language type, Inter-disciplinary technology type and Inter-disciplinary management type", and then they can achieve a sustainable development.

The fittest will survival. Facing new situation, traditional interpreters can't satisfy the current social demand, and only when they change themselves to fit the new circumstance, could they keep competent in future work. Finally, it is hoped that the present study may provide fresh guidance for interpreters, interpretation trainees and interpretation trainers and could enlighten their inspiration to carry out further study and research with interdisciplinary and communicative vision, which is a challenging but rewarding task. There is still much research to be done in this field. Which may bring about many new discoveries? However, these significant tasks rely on interpretation researchers' concentrated devotion and arduous effort in future.

\section{Acknowledgments}

This paper is written for the two research projects. The first project name is "research on cultivating disciplinary foreign language talents in Shaanxi province under the background of new silk road economic zone construction" (15JK1130); the second project name is "research on cultivating disciplinary foreign language talents in China's western region under the background of "The Belt and Road" Construction, which was applied in 2016.

\section{References}

[1] Chai Mingjiong \& Zhang Jiliang. Professionalization in Interpreting: International Experience and Developments in China [M]. Shanghai: Shanghai Foreign Language Education Press, 2016.

[2] Hatim, Basil. Communication across Cultures: Translation Theory and Contrastive Text Linguistics [M]. Shanghai: Shanghai Foreign Language Education Press, 2012.

[3] Newmark, Peter. Approaches to Translation [M]. Shanghai: Shanghai Foreign Language Education Press, 2012.

[4] Katan, David. Translating Cultures: An Introduction for Translators, Interpreters and Mediators [M]. Shanghai: Shanghai Foreign Language Education Press, 2014.

[5] Samovar, Larry A. \& Porter, Richard E. \& Stefani, Lisa A. Communication Between Cultures[M]. Beijing: Beijing Foreign Language Teaching and Research Press, 2012.

[6] Gile, D. Conference Interpreting: Current Trends in Research [M]. Amsterdam: John Benjamins Publishing Co, 1994.

[7] Wadensjo, Cecilia. Interpreting as Interaction [M]. London: Longman, 2008.

[8] Kramsch, C. Language and Culture [M]. Oxford: Oxford University Press, 2013.

[9] Sperper, D. \& Wilson, D. Relevance: Communication and Cognition [M]. Beijing: Foreign Language Teaching and Research Press, 2012.

[10] Hickey, Leo. The Pragmatics of Translation [M]. Shanghai: Shanghai Foreign Language education Press, 2011. 